The author is a social psychologist who was formerly the regional director of the Hemlock Society and President of the Mental Health Association of Marin County. He shares therefore the Californian culture that is, to British eyes, grouporientated, determined to find the right physician and the right counsellor, dedicated to autonomy and believing, like many of its politicians, that almost everything can be solved by open communication and good will if only everyone tries hard enough. Before I read his book I was therefore not overly prejudiced in Dr Jamison's favour.

As I am myself a former hospice physician, with over 5,000 patients dying directly or indirectly under my car, I hoped I was not unacquainted with the common problems of terminal illness. Even if I was not quite as convinced as some colleagues that hospice skills make assisted dying unnecessary and irrelevant as well as illegal, I was ready to resent any proposals for legislation that could invade crudely and simplistically the world of the last illness - one of the last emotional areas not yet submerged in a vulgar showbiz approach.

I have to say that this book's message is a world removed from that. I found the book both moving and instructive. Its raw material comes from some 160 in-depth interviews from 140 assisted deaths covering a period of several years and a broad range of age, social class, attitude and diagnosis.

The variation in the quality of assisted dying is astonishing - from the united family holding hands as their patient slips peacefully away from the dependence and suffering he was now ending, to the inadequate prescription from an unenthusiastic or ill-trained physician or the adulterated street drugs, with the opiates and the barbiturates not working even with extra alcohol and injections, and death finally achieved only with the repellent sadness of a plastic bag over the head and unforgettably awful memories for all those taking part.

It is with this in mind that $\mathrm{Dr}$ Jamison repeatedly emphasises the importance of communication and the sharing of motives - why does the patient really want to die, the supporter to participate, the physician to assist? Clearly these problems must be tackled, yet one is remembering the saintly English priest who said never to investigate motivation, for it is always bad!

Neither keen supporters nor opponents of assisted dying will find too much of comfort in this book, for the author tries to let his participants speak for themselves. Since the fears and expectations of UK patients yearly come to resemble more closely those of American patients, and since family and state both face increased economic pressures, this is a welltimed book for us in the UK.

With the failure of community care and the budgetary problems of the private nursing home, we may find an increase of applications for assisted dying in the next decade. This book helps with the questions even if the ways of thinking, the guidelines and the resources listed are not always helpful to the British reader.

The core material of the casehistories goes beyond frontiers however, and the suffering, the desperation of the onlookers and the kindliness of the author crosses the oceans without difficulty.

ERIC WILKES

Emeritus Consultant,

Trent Palliative Care Centre

\section{Wrong Medicine: Doctors, Patients, and Futile Treatment}

Lawrence J Schneiderman and Nancy $S$ Jecker, Baltimore and London, The Johns Hopkins University Press, 1995, 200 pages, $\$ 25.95$ hc.

The topic of futility raises a number of undoubtedly important ethical issues. The authors argue that some treatments are futile and should not be attempted. They suggest that the goal of medicine is to provide benefit to the whole patient rather than to exert a mere effect on some body part. Doctors and society must recognise the limits both to medicine's powers and to its obligations. Quantitative futility occurs when a treatment has not worked in, say, the last one hundred cases. Whatever the precise figure chosen, they argue that "in the end we all will have to accept some empirical notion of medical futility" (page 162). Qualitative futility is summarised thus: "If a patient lacks the capacity to appreciate the benefit of a treatment, or if the treatment fails to release a patient from total dependence on intensive medical care, that treatment should be regarded as futile" (page 17).

Given the goals of medicine, which help to define futility, the authors anticipate a consensus obligating the avoidance of futile treatment. This will be based on empirical studies with education of the public and the legislature. Declaring a treatment futile will not relieve the physician from the duty to provide good care. Indeed, they assert that good medical practice rests on a correction appreciation of the doctor-patient relationship.

The book aims to change the practice of medicine, particularly as practised (it seems) in the USA. We encounter hospital attorneys and risk managers who sometimes insist, against the advice of physicians and the wishes of the family, that futile treatment should continue; a father disconnects his child's ventilator whilst holding the hospital staff at gunpoint. Being the stuff of American drama it requires hyperbole. Hence, "Patients are almost always in motion, aggressively propelled in search of a cure ..." (pages 3-4); a patient's heart attack requires the use of "a high-voltage cardiac defibrillator" (page 133), as if the voltage causes offence; meanwhile, "The nurses were in constant turmoil" (page 133).

And yet, these goings-on across the Atlantic recall British examples - for example Tony Bland and Child B where the substantive ethical issues were the same. Nor can I personally forget certain patients who have not had good deaths precisely because of the medical "care" heaped upon them. Medical futility is not confined to America.

What of the concept "futility" itself? Is it actually a new and useful tool? Surely medicine has long understood that aiming at a good outcome can end in disaster, that cure is often impossible? These things were known before "futility" entered the medical ethicist's lexicon. Is it then that the concept usefully captures a common feature of disparate ethical issues? But perhaps we should be seeing the differences: here the inappropriate use of technology, there a misplaced value judgment. Any impression that "futility" simplifies may be dangerous, but the book's advocacy of an "ethic of care" is laudable.

Is it true, in any case, that "futility" could be reduced to empirical standards around which a consensus could coalesce? Does it not contain an evaluative judgment as well as a 
factual component? Although resuscitating the last one hundred such patients has failed, may it not be worthwhile to try with this next particular patient? The authors seem to allow that such decisions might be made despite futility guidelines, which is a chink in their armour. For it shows their desire to continue not to lose sight of the individual in a particular context, which reflects an ethic of care.

It might just make sense, after all, for me to persist in my claim that a particular treatment is not futile despite your empirical evidence to the contrary. For this reason "futility" is not quite like the concept of "death", to which it is compared and for which professional guidelines have emerged. Of course, "death" is not a straightforward concept, but I am suggesting that it is more factual and less evaluative or ethical than "futility". I am not disputing that some treatments are futile for some patients, but it is the particularity that counts, which is so essential to the doctor-patient relationship. And obligating definitions of futility may endanger that relationship.

The use of futility as a means of combating claims based on autonomy seemed to me clever. However, a professional consensus that my treatment is futile (even if supported by the courts) might still be paternalistic, overriding my claim to autonomy. This is because "futility" is a valueconcept more than an objective standard. So why use "futility" at all? Why not just argue on other grounds against autonomy and for certain sorts of paternalism?

Finally, I have a concern about futility in dementia. True, the authors recognise the need for "comfort care" and the need to treat symptoms which the patients might be experiencing. But the demented might well lack "the capacity to appreciate the benefit of a treatment", in which case the treatment "should be regarded as futile". They argue that for demented Mrs Boxley a feeding tube was bound to prolong her agony and be thereby futile. This is not a factual point, but an ethical stance and should be regarded as such. Moreover, from the information given, I think she may have been depressed. The gastrostomy might have been a mistake, but to declare her treatment futile, to allow her to starve to death (with dignity), would have been negligent if (low voltage) electroplexy could cure her! I suspect that severe dementia might, in general, invalidate a subject's claim to personhood in the authors' required sense and so always make the subject prey to the suggestion that further treatment is futile.

I commend this clearly written, trenchantly argued book to all with an interest in medical ethics, not because of its thesis concerning futility, but because of the important issues it raises. As for futility, I remain to be convinced that it is a notion which will solve substantial issues in medical ethics.

JULIAN C HUGHES Rivendell Assessment Centre, Radcliffe Infirmary, Oxford

\section{Animal-to-human Transplants: the Ethics of Xenotransplantation}

Nuffield Council on Bioethics,
London, Nuffield Council on
Bioethics, 1996, 147 pages, $£ 10$.

This report from the Nuffield working party, which was convened in January 1995, surveys developments in xenotransplantation, considers whether there are effective alternatives, and assesses arguments regarding the ethical acceptability of animal-to-human transplants. The report focuses mainly on proposals to use primates and transgenic pigs for transplantation purposes.

The arguments in favour of xenotransplantation appeal to the shortage of human organs, which is unlikely to be resolved in the foreseeable future, and the number of human lives that would be saved, with their quality improved. Xenotransplantation, so it is argued, would also avoid awkward ethical dilemmas concerning the use of human tissue, such as the problems associated with donor consent and the controversial use of tissue from aborted fetuses.

The arguments against xenotransplantation fall into two categories. Both are surveyed in depth in this report. First, there are problems concerning the predicted success rate of xenotransplants. Are they likely to be scientifically feasible, and what are the risks to recipients and the population in general? To date there has been little success with xenotransplants, largely because of rejection by the recipient's immune system. Two approaches to this problem hate been proposed. They involve a) the use of baboon organs, as their genetif closeness to humans indicates reduced likelihood of rejection, and b) the use of genetically modifi pigs, whose organs would not raise such a strong response in the huma recipient. The latter proposat involves altering the genetic make-up of the pig by introducing humant genetic material, thus producing transgenic pigs. Critics are sceptic बלt with regard to the predicted succe rates and raise doubts regarding the hazards to the recipient and of the potential public-health risk from infectious organisms transmitteid from animals to humans. It has als $\vec{\Phi}$ been argued that further steps in the direction of xenotransplantatio might have an adverse effect on human donation.

The second category of problems. concerns the welfare of non-human animals. Critics argue that a large scale programme of xenotransplantation would represent the ultimate steg in the treatment of animals as dispos able objects. The report consequent endorsed widely held moral objections against primate organ transplantatio not merely because of claims that theif evolutionary closeness suggested qua $\vec{B}$ ities which would entitle them to the protection afforded to members of moral community, but also from we fare considerations concerning regime of breeding and maintainin these intelligent social beings. $T_{\theta}$ avoid the risk of transmitting diseases. to humans, primates selected for xen $\dot{8}$ transplantation would have to bo reared in isolation and their environ ment strictly controlled. Nevertheles the report does support the use transplants from transgenic pigs. despite the fact that their welfare intero ests might be compromised by the requirement to keep them in a disease free, sterile, and monotonous, isolated environment. In consideration of the problems the report recommendey that attention be paid to means of reducing adverse effects associate with the need to produce animals free from infectious organisms. The repot also stressed an urgent need to esta애 lish an advisory committee on xenळ transplantation for the purpose assessing the potential public-health risk from infectious organisms. It also recommended steps to protect patients who receive xenografts and to ensure that patients who refuse them are nef; denied human organs or disadvan taged in any way. 